\title{
Evaluation of shiitake strains (Lentinula edodes) on selective lignin degradation in Miscanthus $x$ giganteus
}

A.S.M. Sonnenberg, Johan J.P Baars, M.H.M. Visser, B. Lavrijssen, J.W. Cone \& P.M. Hendrickx

WageningenUR, Plant Breeding

This study was carried out by Wageningen UR (University \& Research centre) and was commissioned and

financed by the Dutch Ministry of Economic Affairs, Productschap Tuinbouw, C4C Holding and Dyadic.

Wageningen UR is the collaboration of Wageningen University and the foundation Stichting Dienst Landbouwkundig Onderzoek.

Wageningen, December 2016 
A.S.M. Sonnenberg, J.J.P Baars, M.H.M. Visser, P. Lavrijssen \& P.M. Hendrickx, 2016. Evaluation of shiitake strains (Lentinula edodes) on selective lignin degradation in Miscanthus $x$ giganteus.

Wageningen, the foundation Stichting Dienst Landbouwkundig Onderzoek. Research Institute Praktijkonderzoek Plant \& Omgeving / Plant Research International, Wageningen UR (University \& Research centre), PPO/PRI report 2016-X

Keywords: Lentinula edodes, Miscanthus, lignin, biological pretreatment

(C) 2016 Wageningen, Stichting Dienst Landbouwkundig Onderzoek, Research Institute Praktijkonderzoek Plant \& Omgeving/Plant Research International, P.O. Box 16, 6700 AA Wageningen, The Netherlands; T +31 (0)317 4807 00; www.wageningenur.nl/en/XX

Chamber of Commerce no. 09098104 te Arnhem

VAT NL no. 8065.11.618.B01

Stichting Dienst Landbouwkundig Onderzoek (DLO Foundation). All rights reserved. No part of this publication may be reproduced, stored in an automated database, or transmitted, in any form or by any means, whether electronically, mechanically, through photocopying, recording or otherwise, without the prior written consent of the DLO Foundation.

DLO is not liable for any adverse consequences resulting from the use of data from this publication.

PPO/PRI report 2016-X

Photo cover: $\mathrm{XXXX}$ 


\title{
Contents
}

\section{Table of Contents}

\author{
Contents 3
}

Summary 4

Introduction

5

Materials \& Methods

6

Results 7

3.1 The selection of shiitake strains from the collection 7

3.2 Vegetative growth on Miscanthus 7

3.3 Fibre analysis $\quad 7$

3.4 Correlations between dry matter degradation and fibre content. $\quad 8$

4 Conclusions $\quad 13$

$5 \quad$ References $\quad 14$

6

Appendix

15

$6.1 \quad 6.1$ Strains used

15

6.26 .2 Images of colonization 16

7

18

6.3 Statistical analysis (Only for samples $t=9$ weeks) 


\section{Summary}

After genotyping 90 strains of Lentinula edodes (shiitake) of the Plant Breeding collection, a selection of 20 strains was made that represented the genetic variation in the collection. These strains were inoculated on sterilized Miscanthus $\mathrm{x}$ giganteus stems and incubated for 9 weeks. Samples were taken after 3, 6 and 9 weeks and analysed for fibre degradation. A large variation was found in colonisation between strains resulting in differences in dry matter degradation. Slow growing strains hardly

changed the fibre content of Miscanthus whereas fastest growing strains degraded up to $42 \%$ of lignin and $35 \%$ of hemicellulose resulting in an increase of $28 \%$ of cellulose. A good correlation was found between lignin and hemicellulose degradation and loss of dry matter indicating that predominantly these 2 compounds are degraded resulting in an increase of cellulose content. There was also a good correlation with the extend of this degradation pattern and the increase in in vitro gas production, an indication of digestibility by ruminants.

The large variation found between strains indicate potentials for breeding shiitake for an improved selective degradation of lignin and upgrading Miscanthus for different downstream biobased applications. 


\section{Introduction}

The shiitake mushroom (Lentinula edodes) is one of the most cultivated edible mushrooms in Eastern Asia and an increasing popularity is seen in Western countries. Most fresh products in Europe are imported from China and an improved production system will help to increase the local production. This also includes the use of varieties with an improved yield and quality. Next to the production of edible mushrooms, this species can also be used to upgrade lignocellulose materials. The shiitake mushroom is a white rot fungus that can degrade lignin selectively in lignocellulosic materials (degradation of lignin while hardly any cellulose is degraded; (Tuyen et al. 2013);(Kuijk 2016)). This will facilitate the access to the polysaccharide cellulose, a source for the generation of bioenergy and bioplastics. In addition, the selective removal of lignin with a white rot fungus increases the digestibility for ruminants (Kuijk 2016) and when for this purpose white rot fungi are used that produce edible mushrooms, the treated substrate is generally considered as safe (GRAS) and thus suitable as an animal feedstock.

Most research done on selective degradation of lignin by white rot fungi has been directed to screening of fungal species and substrate combinations. Hardly any research has been done to evaluate the performance of strains within one species. Next to our own research (Kuijk et al. 2015), we have found only one paper in peer reviewed journals that evaluated the effect of shiitake growth on the fibre composition of Miscanthus and this the authors used only one strain (Baker et al. 2016). The fungal collection of Wageningen UR Plant Breeding (WUR-PB) contains a large number (99) of strains and a proper genotyping of these strains have not been done so far. The collection have been build-up in the last 40 years by exchanging strains with other collections, sampling from commercial spawn or gifts from third persons. The genetic variation within the shiitake collection has been evaluated previously (Sonnenberg et al. 2015). For this report, a selection of 20 strains representing the genetic variation in the collection, has been grown on Miscanthus $x$ giganteus for 3, 6 and 9 weeks. A good performance (high lignin degradation in combination with a low cellulose degradation) makes a strain useful for upgrading lignocellulose but might also benefit the production of fruiting bodies.

Degradation of lignin enhances the access to polysaccharides and can thus potentially improve also mushroom yield. 


\section{Materials \& Methods}

All strains from the Lentinula edodes (20 strains) have been grown on MMP medium and used to generate spawn on Sorghum grains as described before (Kuijk et al. 2015). For each strain and time point two trays were used, each filled with ca 250 gram Miscanthus (wet).

Miscanthus $x$ giganteus was collected from a trial plot at Unifarm Wageningen UR. The fungal

treatment of these materials was done as described in Kuijk et al. (Kuijk et al. 2015). Fibre analysis was performed according to the method of Van Soest et al. (Van Soest et al. 1991)and described in more details in (Kuijk et al. 2015).

In vitro gas production (IVGP72) technique: In vitro gas production was performed according to the procedure described by(Cone et al. 1997). In summary, rumen fluid of fistulated non-lactating cows fed a grass silage based diet was mixed with an buffer solution under anaerobic conditions. Air dried samples (500 mg) were incubated in $60 \mathrm{ml}$ buffered rumen fluid for $72 \mathrm{~h}$ at $39 \circ \mathrm{C}$. The gas production was recorded automatically as described by (Cone et al. 1997) and related to the organic matter (OM) content of the samples. 


\section{Results}

\subsection{The selection of shiitake strains from the collection}

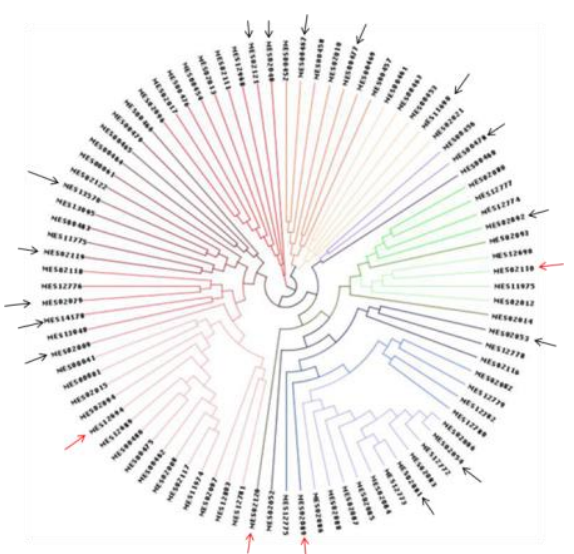

Figure 1. Dendrogram of the Lentinula edodes strains in the collection of Plant Breeding. Strains were genotyped using AFLP. Arrows indicate the lines that were selected for growth on Miscanthus.

In the previous report (Sonnenberg et al. 2015), we have presented the genotyping of all shiitake strains in the collection of Plant Breeding based on the AFLP analysis. From the genetic diversity, a selection of 20 lines was made representing the genetic diversity of the collection (Figure 1). The origin of the strains are given in the Appendix (Table A1). Most strains originate from Eastern Asian (mainly China and Japan) and are or have been used in commercial cultivations. For some strain the origin is unclear.

\subsection{Vegetative growth on Miscanthus}

The strains show a large variation in vegetative growth on Miscanthus during the 9 weeks of incubation. Four strains have a very thin growth and formed even after 9 weeks of incubation not much mycelium (Mes \# 12694, 02120, 02089, 02110 and 02119). All other strains grow well or very well. There is some correlation between the strength of mycelial growth and the time and extend of browning and formation of brown exudate (see in Appendix Figure A1). This correlates also somewhat with the degradation of lignin. The exudates of mycelium is a complex mixture contains also phenols (Huang et al. 2011) and might thus result from the degradation of lignin.

\subsection{Fibre analysis}

There is a large variation in loss of dry matter between strains during 9 weeks of incubation (figure 2). As expected, strains that show a very slow growth and formed not much mycelium did also not degrade much dry matter. All fast growing strains showed a considerable degradation of dry matter in time with averages of $6 \%$ after 3 weeks, $13 \%$ after 6 weeks and $19 \%$ after 9 weeks. A few strains degraded more than $20 \%$ of the dry matter after 9 weeks (up to $25 \%$ ).

The fibre composition of all samples were analyses with the ANKOM (automated van Soest analysis). All samples were done in triplicate and averaged. Due to the a large variation, most differences are not significant (appendix table 2) and the data presented are more an indication of trends. The acid detergent lignin (ADL) was used as an estimate of the lignin content of Miscanthus. A clear difference was seen between the strains (figure 3 ) with a progress in lignin degradation during incubation. The strains that show a very thin growth did hardly degrade any lignin in Miscanthus. The best strains degrade up to $42 \%$ of the lignin (figure 3 ). As seen with other fungi, L. edodes prefers the utilisation of hemicellulose for vegetative growth (figure 4). For hemicellulose degradation clearly two groups can be seen. The first group of 4 strains cause hardly any decrease in hemicellulose content. These strains also show a very thin growth. The second group shows a considerable degradation of hemicellulose and all to a similar extend. The decrease in hemicellulose content can be as much as $40 \%$. One additional strains (MES02119) that shows a poor mycelial growth does produce some exudates and shows also a clear degradation of hemicellulose (figure A1). This might suggest a correlation between 
exudate production and hemicellulose degradation. Most strains caused an increase in cellulose content due to the selective degradation of lignin and hemicellulose (figure 5). The best 2 strains increased the cellulose content with $29 \%$. For the slow growing strains, again hardly any change in cellulose content was seen compared to untreated Miscanthus.

\subsection{Correlations between dry matter degradation and fibre content.}

The degradation of dry matter correlated well with the lignin and hemicellulose content (figure 6). The higher the dry matter loss, the lower the hemicellulose and lignin content. Cellulose content had a positive correlation with dry mater degradation, i.e. the more dry matter is degraded, the higher the cellulose content. This patters demonstrates that the fungi degrade primarily hemicellulose and lignin during vegetative growth and as a result enrich the organic matter in cellulose content. The simultaneous degradation of hemicellulose and lignin results in a positive correlation between hemicellulose and lignin change between the strains (figure 6). As a result, the degradation of hemicellulose and lignin correlates negatively with the cellulose content.

\subsection{In vitro gas production (IVGP)}

The fungal treated Miscanthus samples were used to test the digestibility by ruminant microorganisms in the IVGP system describes earlier (Cone et al., 1997). A large variation is seen in the IVGP between strains (figure 7). Except for the slow growing strains, all strains showed an increase in IVGP during after incubation for 6 to 9 weeks. The increase varied from 30 up to $113 \%$ increase in IVGP. The IVGP correlated well with the decrease in lignin and increase in cellulose content (figure 8). This shows clearly that the shiitake strains enhance the digestibility of Miscanthus by removing lignin and thus enrich Miscanthus in cellulose content. 


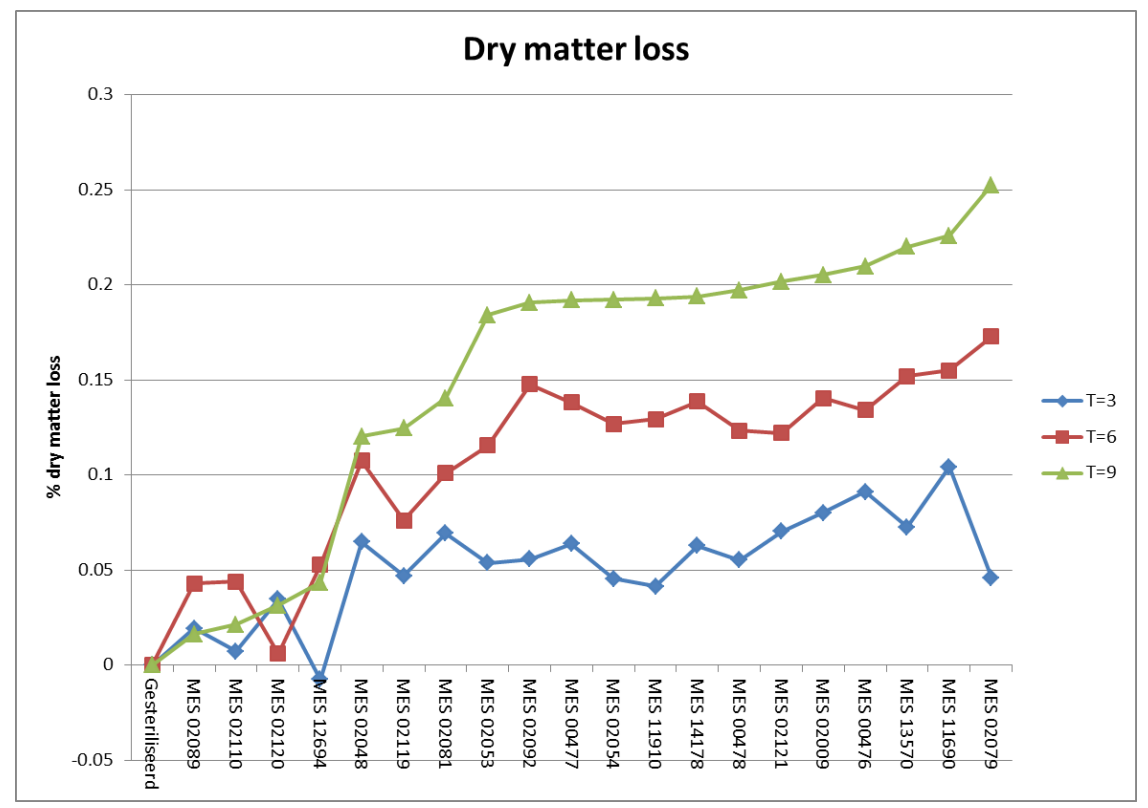

Figure 2.Dry matter loss in Miscanthus after colonization by different strains of $L$. edodes. 

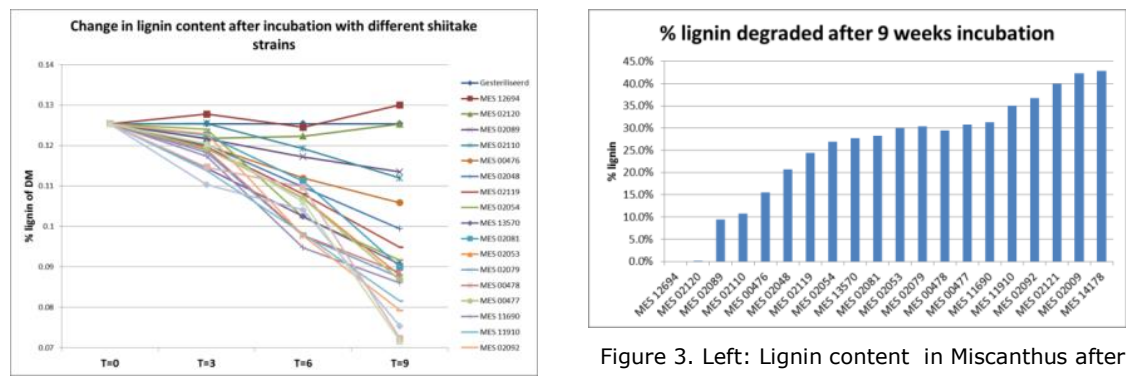

Figure 3. Left: Lignin content in Miscanthus after 3, 6 and 9 weeks of incubation with different shitake strains, ranked to degradation after 9 weeks. Right: \% of lignin degraded by 20 strains ranked after 9 weeks of incubation.
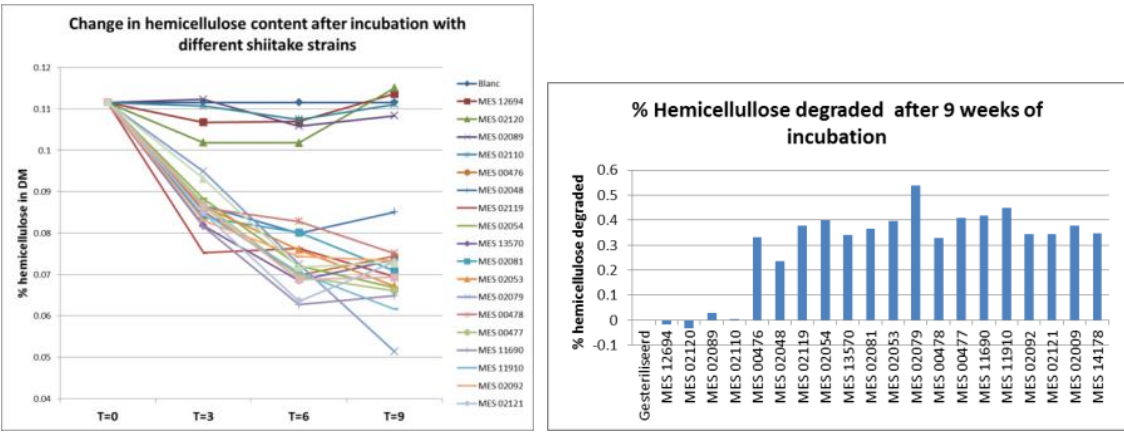

Figure 4. Left: Hemicellulose content in Miscanthus after 3, 6 and 9 weeks of incubation with different shitake strains (ranked to degradation of lignin after 9 weeks). Right: \% of hemicellulose degraded after 9 weeks of incubation with 20 strains (ranked after lignin degradation after 9 weeks).
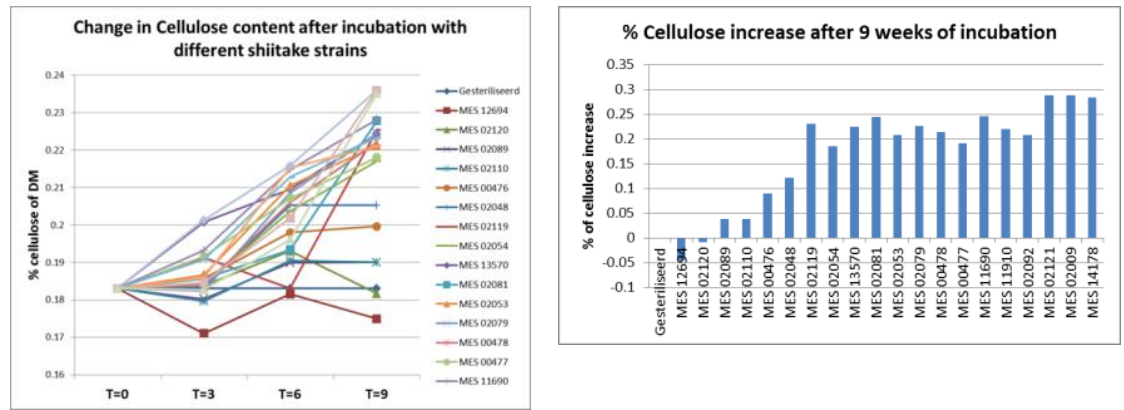

Figure 5. Left: Cellulose content in Miscanthus after 3, 6 and 9 weeks of incubation with different shitake strains (ranked to degradation of lignin after 9 weeks). Right: \% increase in cellulose content of Miscanthus after 9 weeks of incubation with 20 strains (ranked after lignin degradation after 9 weeks). 

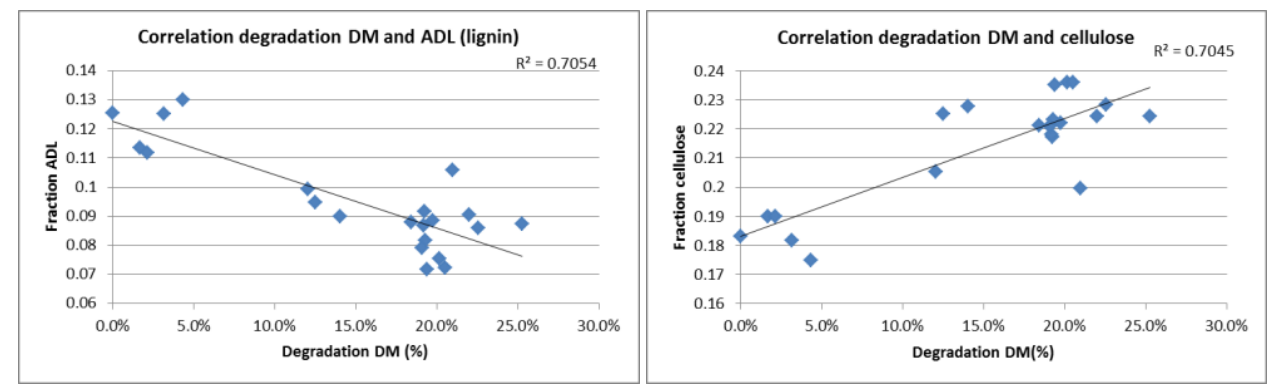

Correlation degradation DM and Hemicellulose

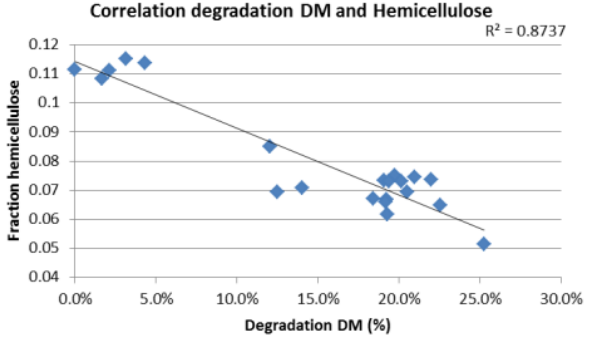

Correlatie ADL en hemicellulose afbraak (fracties)
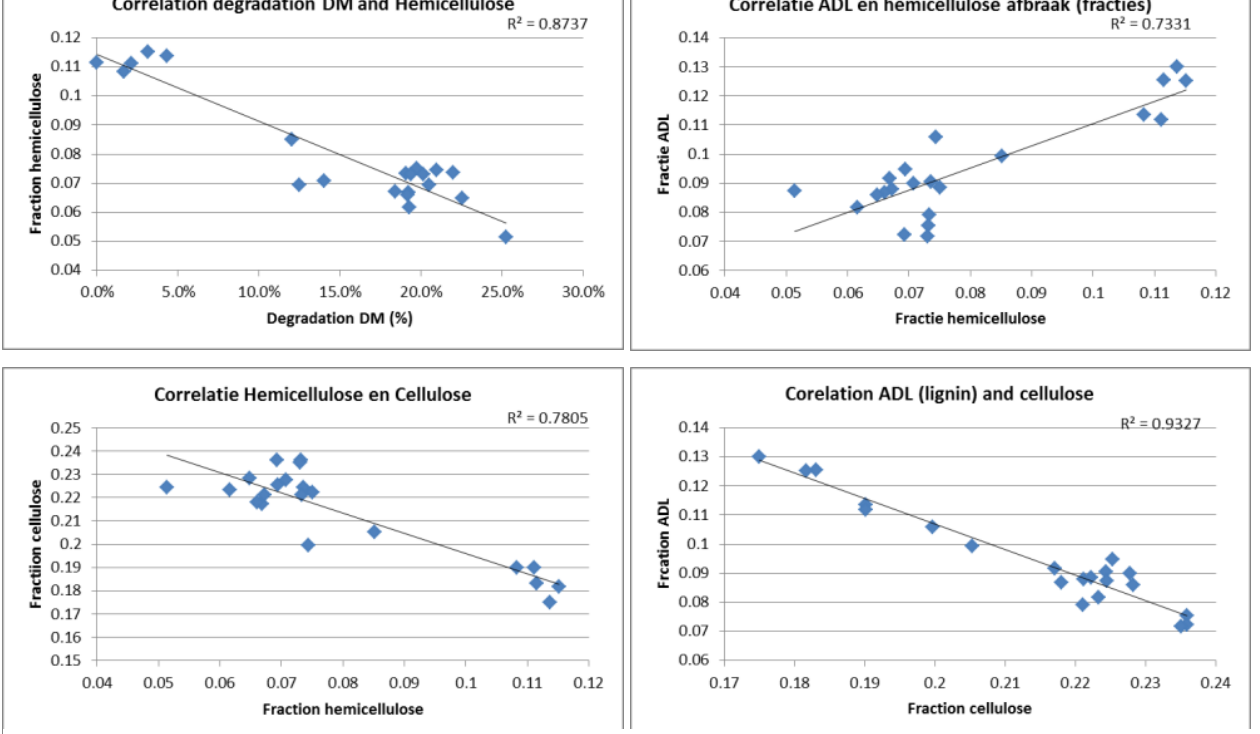

Figure 6. Correlations between fibre degradation (expressed as fraction of fibre content) and dry matter degradation (\% degradation) over all strains used after 9 weeks of incubation. Negative correlations are seen between DM degradation and lignin and hemicellulose content, indicating that these 2 components are the main fibres that are degraded. There is also a negative correlation between degradation of hemicellulose and cellulose, and lignin and cellulose. This indicates that the degradation of hemicellulose and lignin leads to an increase of cellulose. As a result, there is also a positive correlation between dry matter degradation and cellulose content. 


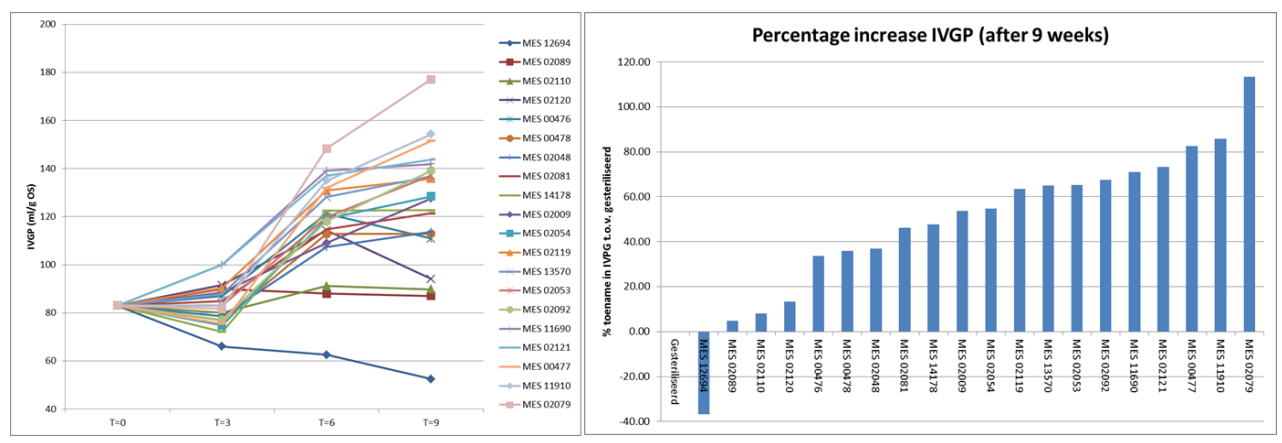

Figure 7. Effect of fungal treatment on the in vitro gas production (IVGP) by ruminant microorganisms. For all strains that show a clear growth, the IVGP is increasing between 3 and 9 weeks of fungal growth (left). The increase compared to untreated Miscanthus. Strains that show a low grow had a negatively or very small positive effect on IVGP. For all strains that show a clear growth, the increase of the IVGP varied between 30 and $113 \%$ (right).
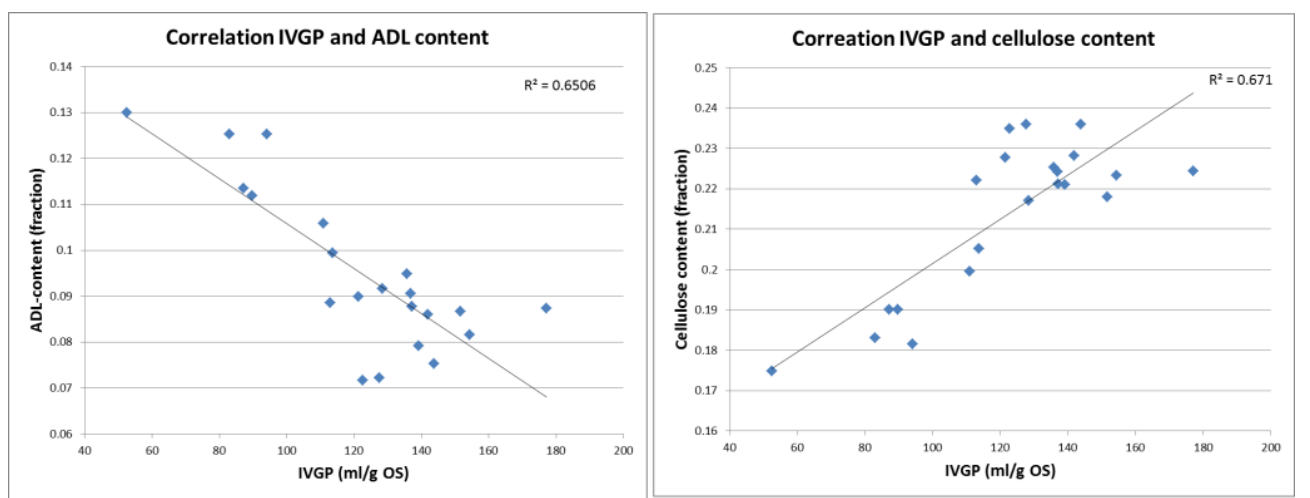

Figure 8. Correlations between IVGP and the lignin (left) and cellulose (right) content. The removal of lignin and thus an enrichment of cellulose has a clear positive effect on the IVGP. 


\section{Conclusions}

We have selected 20 strains of Lentinula edodes (shiitake) in such a way that they represent the genetic variation for this species in our collection. A large variation in growth on sterilized Miscanthus was observed. Strains that grow well produce exudates after 9 weeks and some even after 6 weeks of incubation, causing browning of the substrate. This vegetative maturation is also needed to have a successful mushroom production.

Ca. 4 strains had difficulties to colonies Miscanthus even after 9 weeks of incubation. These strains also produced no exudate. From 2 of these strains we know they are or have been used for commercial mushroom production. A good growth on pure lignocellulosic material is thus not a prerequisite for a good mushroom production. That can be explained by the supplements used by mushroom growers in the substrate such as maize meal, wheat/rice bran etc. Miscanthus might thus be used purely as a carrier for easy to degrade nutrients as is done for saw dust now. The experiments show, however, that $L$. edodes is capable of degrading Miscanthus and can thus in principle be used as a substrate.

L. edodes appears to be good degraders of lignin although it takes time. The best strains can reduce lignin with $42 \%$ after 9 weeks. Another white-rot fungus, Ceriporiopsis subvermispora, seems to do better. C. subvermispora can reduce lignin in wheat straw with almost $70 \%$ within 5 weeks, whereas L. edodes reduces lignin with $33 \%$ in the same period (Kuijk 2016). A longer incubation ( 8 weeks) increase the reduction of lignin to $60 \%$. There is only one publication of degradation of Miscanthus by C. subvermispora (Baker et al. 2016). In this work an unknown strain was used on Miscanthus sacchariflorus and no absolute values were given, thus difficult to compare to our data.

$L$. edodes can be designated as a selective degrader since mainly lignin and hemicellulose are degraded resulting in an increase of cellulose content. One has to keep in mind, however, that the amount of hemicellulose was measured as the difference between NDF and ADF fractions. NDF is the residue after neutral detergent extraction and it is well possible that part of the hemicellulose is solubilised by the fungus and not consumed and might thus disappear after NDF extraction. Jurak and colleagues (Jurak et al. 2015) have shown, for example, that the button mushroom dissolves hemicellulose partly during vegetative growth.

The degradation of lignin by white rot fungi is mainly done by generating small radical molecules that diffuse into the dense lignin and break bonds between phenolic building blocks. This process is not very specific and there are indications that these radicals also etches the crystalline cellulose fibres (López-Abelairas et al. 2013). This will increase the digestibility of cellulose by enzymes. The increase in glucose per unit biomass after enzymatic digestion is thus not only due to the enrichment of cellulose but likely also to the increase in degradability of cellulose. A clear effect of the fungal treatment on Miscanthus is the increase in IVGP by ruminant microorganisms. The best strains even increases the IVGP with $113 \%$. This increase in IVGP correlates well with the decrease of lignin and increase of cellulose content.

The large variation in selective degradation offers an opportunity to increase the performance by breeding. A combination with other (physical/thermal) treatment might improve the biological treatment to such an extent that is comparative with the now a days used physical and/or thermal treatments. 


\section{$5 \quad$ References}

Baker PW, Winters A, Hale MDC (2016) Biodegradation of Different Genotypes of Miscanthus by Wood Rot Fungi. Bioresources 11(2):12

Cone JW, van Gelder AH, Driehuis F (1997) Description of gas production profiles with a three-phasic model. Animal Feed Science and Technology 66(1):31-45 doi:http://dx.doi.org/10.1016/S03778401(96)01147-9

Huang W, Kim J-S, Chung HY (2011) Antioxidant activity and total phenolic content in shiitake mycelial exudates. Natural Product Communications 6(6):6

Jurak E, Punt AM, Arts W, Kabel MA, Gruppen H (2015) Fate of Carbohydrates and Lignin during Composting and Mycelium Growth of Agaricus bisporus on Wheat Straw Based Compost. PloS one:16 doi:DOI: 10.1371

Kuijk SJAv (2016) Fungal treatment of lignocellulosic biomass (Doctoral dissertation). Retrieved from http://edepot.wur.nl/370642.

Kuijk SJAv, Sonnenberg ASM, Baars JJP, Hendriks WH, Cone JW (2015) Fungal treatment of lignocellulosic biomass: Importance of fungal species, colonization and time on chemical composition and in vitro rumen degradability. Animal Feed Science and Technology 209:40-50

López-Abelairas M, Álvarez Pallín M, Salvachúa D, Lú-Chau T, Martínez MJ, Lema JM (2013) Optimisation of the biological pretreatment of wheat straw with white-rot fungi for ethanol production. Bioprocess and Biosystems Engineering 36(9):1251-1260 doi:10.1007/s00449-012-0869-z

Sonnenberg ASM, Visser MHM, Lavrijssen B, Hendrickx PM (2015) Evaluation of king oyster mushrooms strains (Pleurotus eryngii) on selective lignin degradation in wheat straw. WUR Report

Tuyen DV, Phuong HN, Cone JW, Baars JJP, Sonnenberg ASM, Hendriks WH (2013) Effect of fungal treatments of fibrous agricultural by-products on chemical composition and in vitro rumen fermentation and methane production. Bioresource Technology 129:256-263

Van Soest PJ, Robertson JB, Lewis BA (1991) Methods for Dietary Fiber, Neutral Detergent Fiber, and Nonstarch Polysaccharides in Relation to Animal Nutrition. Journal of Dairy Science 74(10):35833597 doi:http://dx.doi.org/10.3168/jds.S0022-0302(91)78551-2 


\section{Appendix}

\section{$6.1 \quad 6.1$ Strains used}

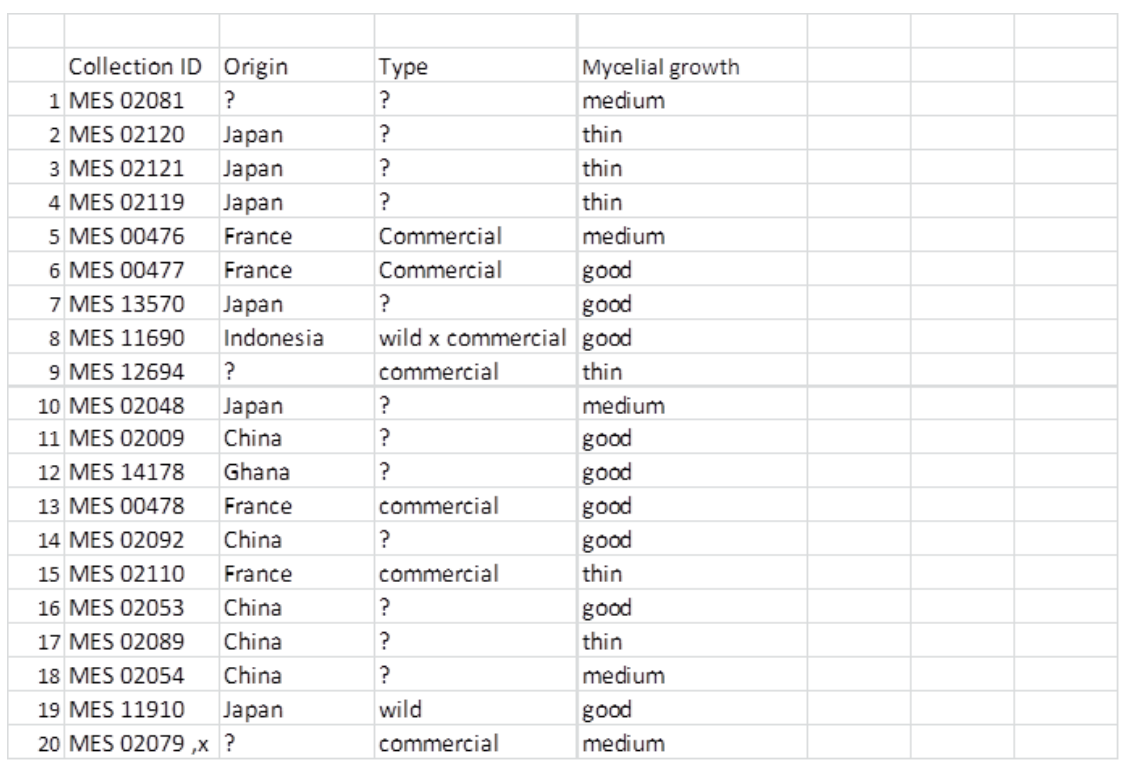

Table A1. Lentinula edodes strains of the Plant Breeding collection used in the study of degradation of fibres in Miscanthus. Not from all strains the exact origin is known. The last column indicates the vegetative growth on Miscanthus (visual examination). 
$6.2 \quad 6.2$ Images of colonization

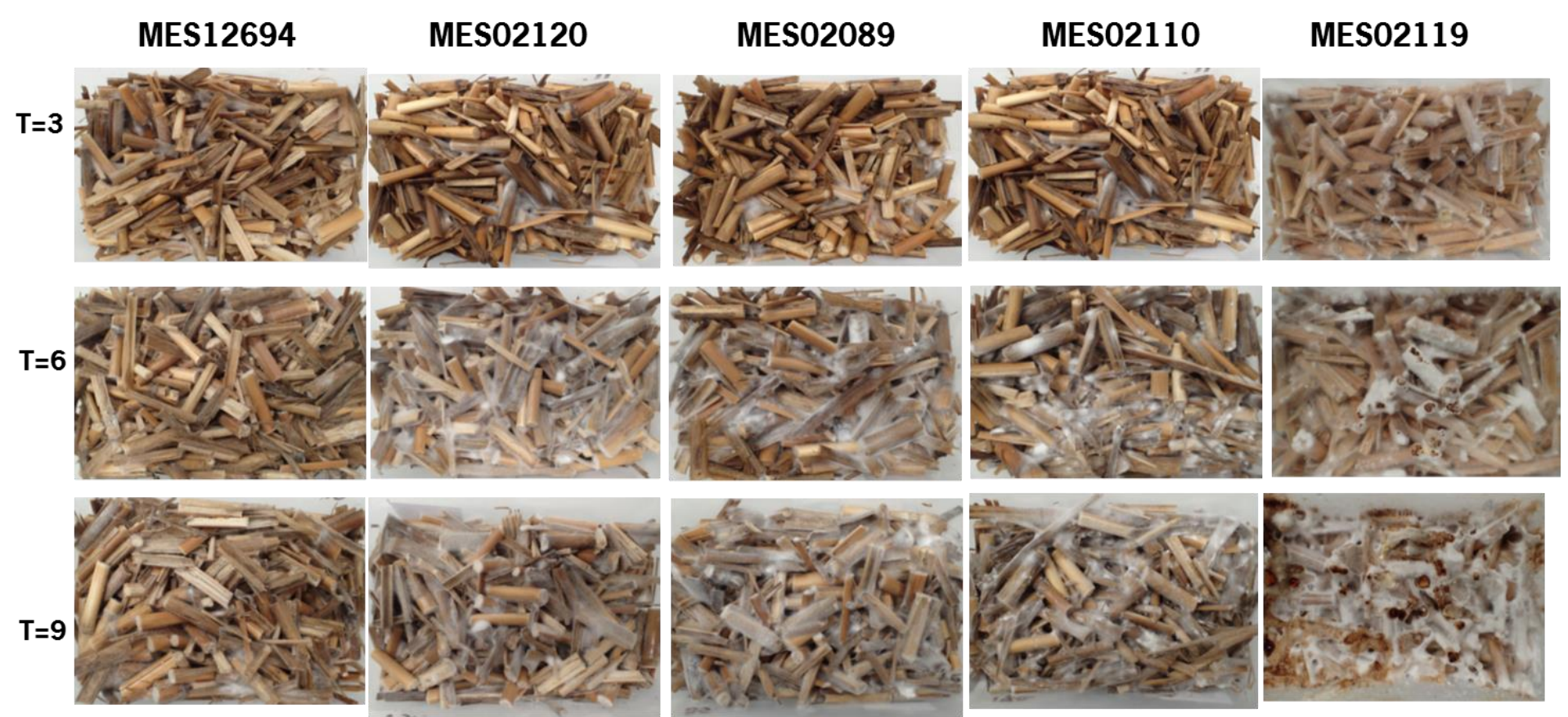

Thin mycelial growth; no exudate in the first 4 and a little exudate in the last strain. 


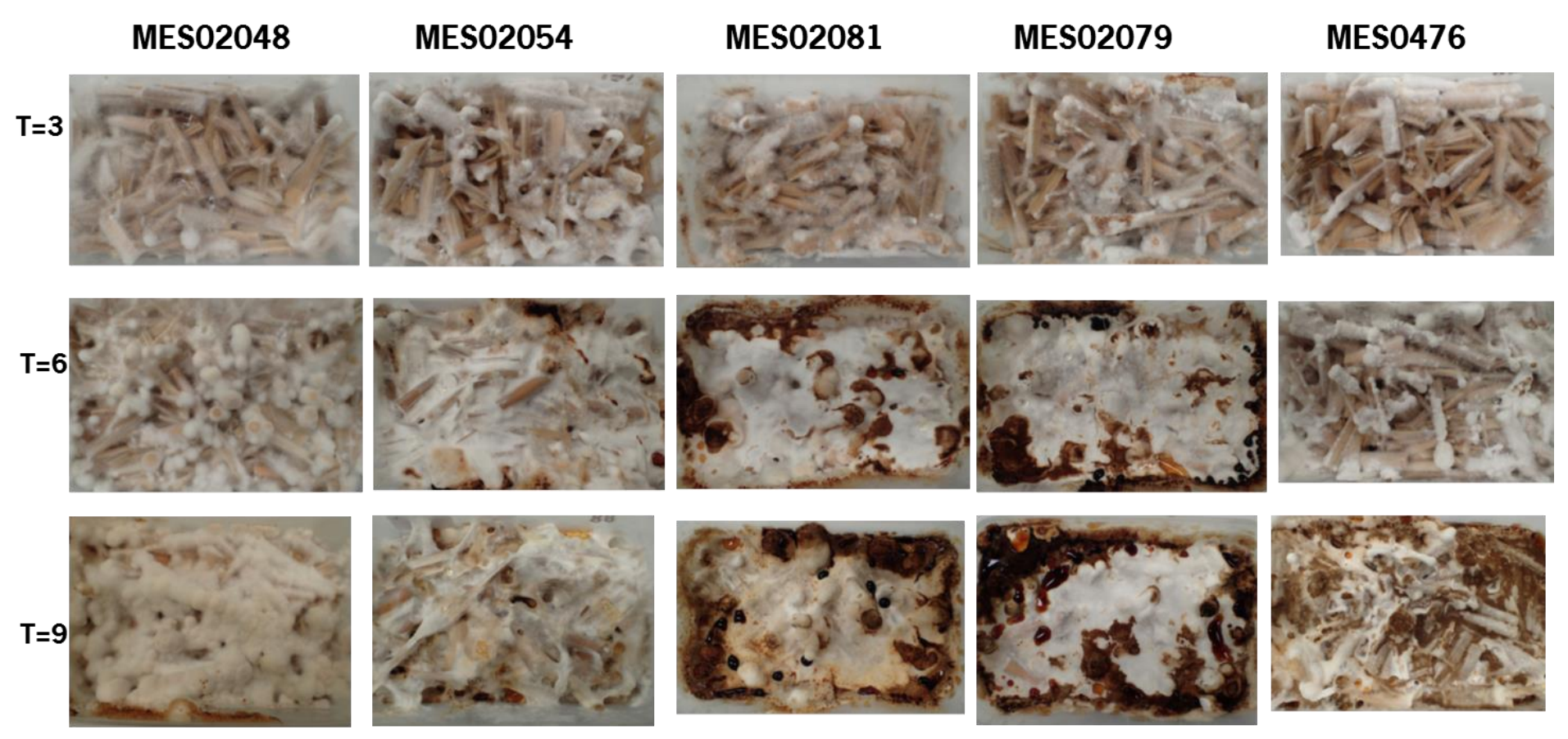

Medium mycelial growth 

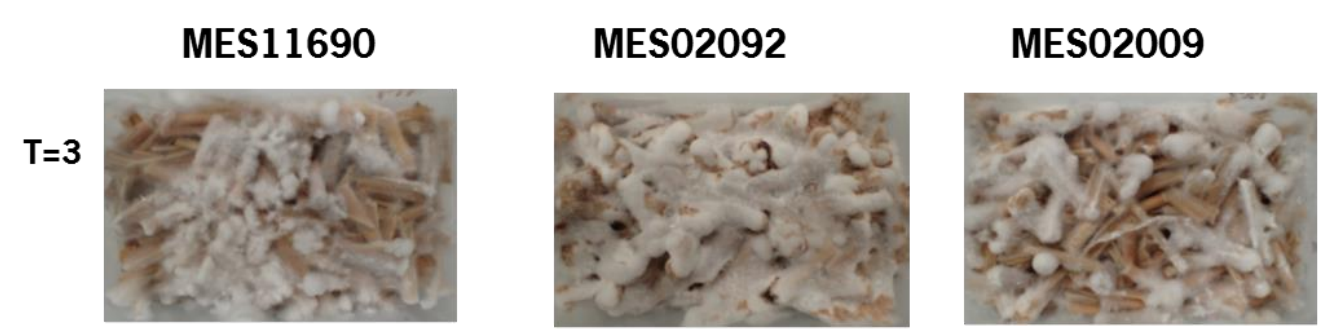

\section{MES14178}

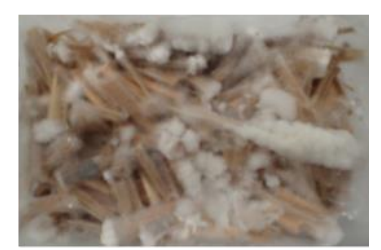

$T=6$
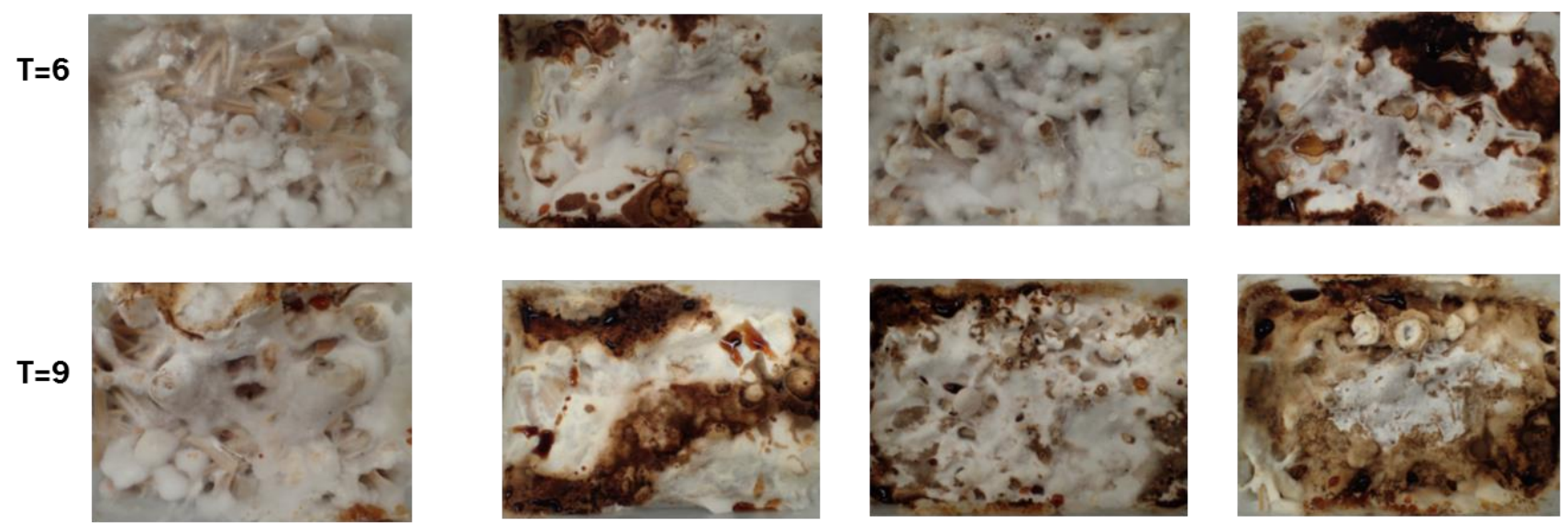

Good mycelial growth 


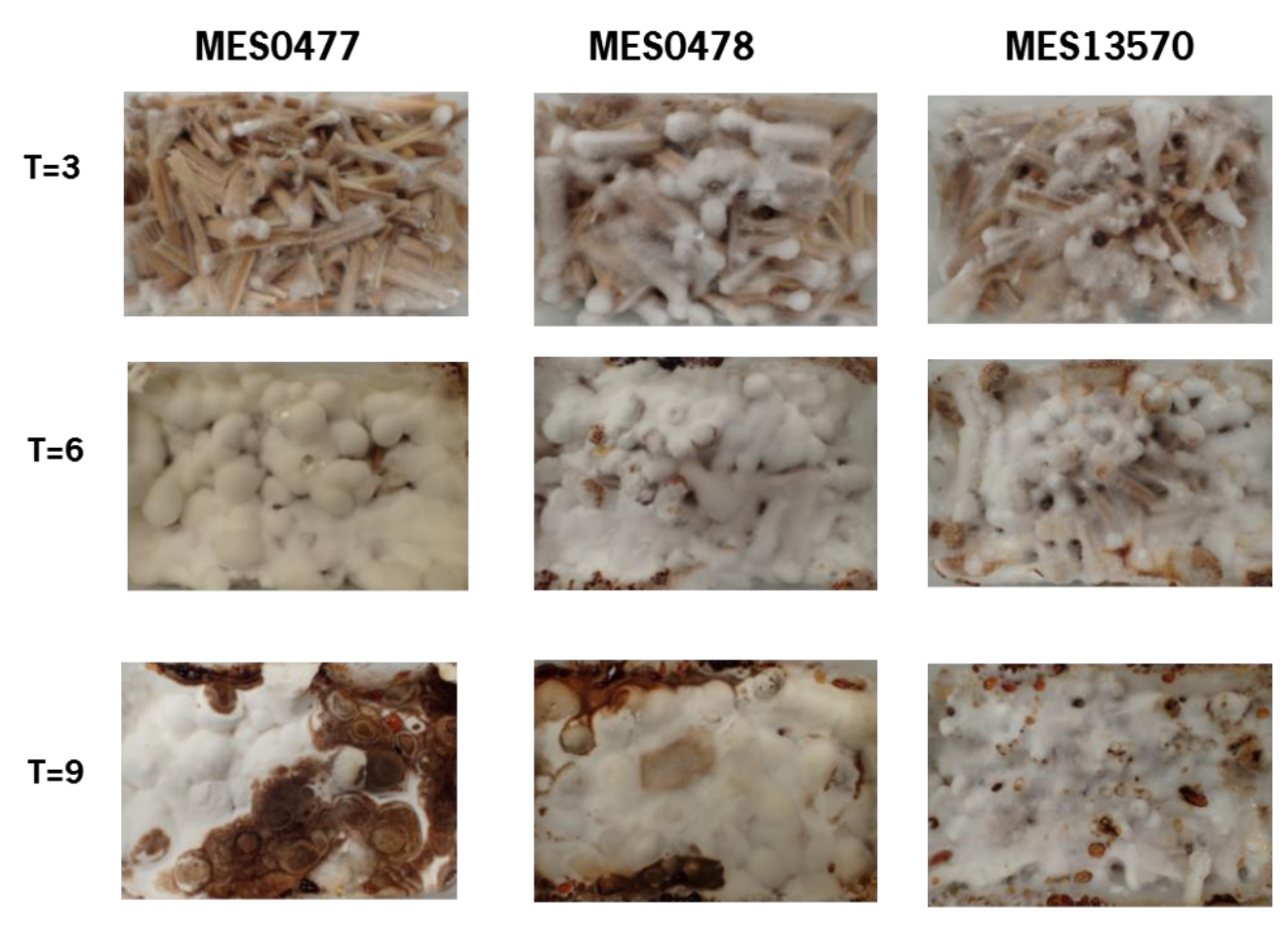

Good mycelial growth 


\subsection{Statistical analysis (Only for samples $t=9$ weeks)}

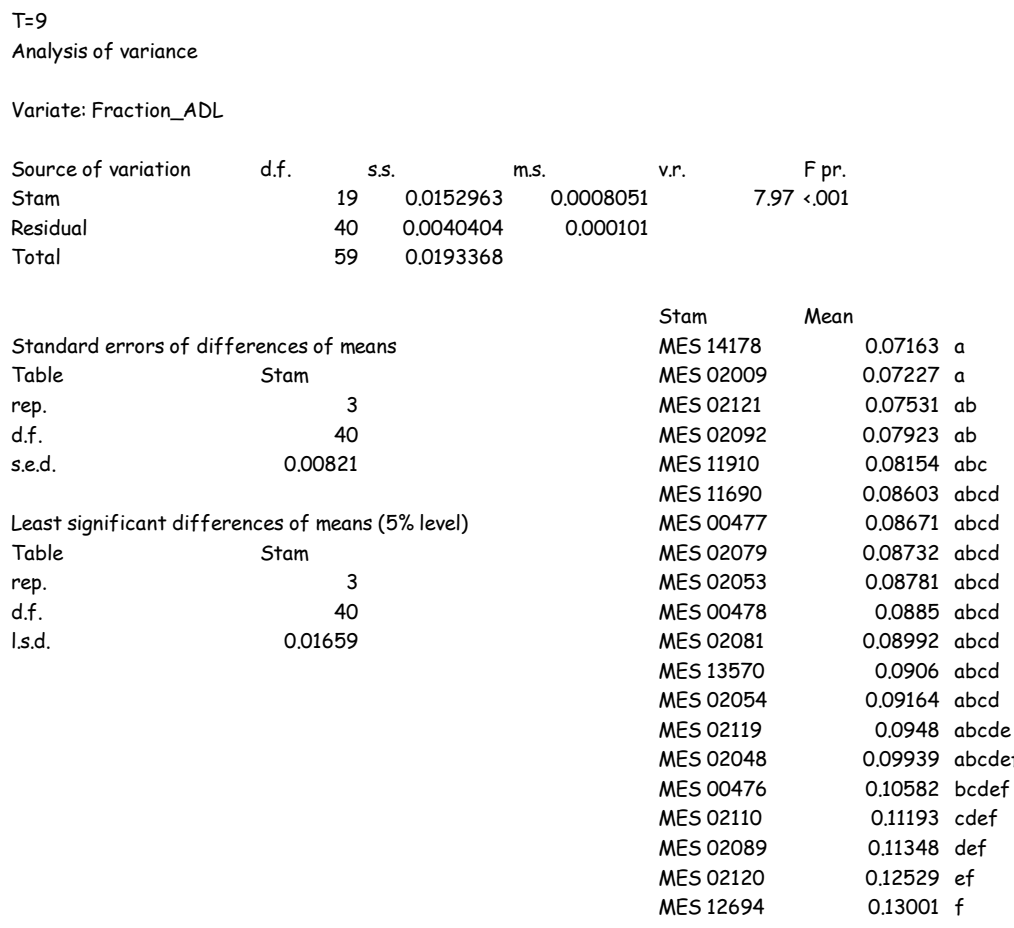

$T=9$

Analysis of variance

Variate: Fraction_NDF

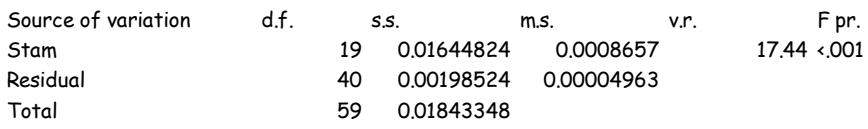

Standard errors of differences of means

Stam Mean

Table Stam

$\begin{array}{lr}\text { rep. } & 3 \\ \text { d.f. } & 40 \\ \text { s.e.d. } & 0.005752\end{array}$

Least significant differences of means ( $5 \%$ level)

MES 02079

$0.3708 a b c$

MES $02092 \quad 0.3736 a b c$

MES $02054 \quad 0.3755 \mathrm{abc}$

MES $02053 \quad 0.3762 a b c$

MES $02009 \quad 0.3775 a b c$

MES $11690 \quad 0.3791 \mathrm{abc}$

MES $14178 \quad 0.3796 a b c$

MES $00476 \quad 0.3798 a b c$

MES $02121 \quad 0.3843 a b c$

MES $00478 \quad 0.3857 b c$

MES $02081 \quad 0.3884 c$

MES $13570 \quad 0.3884 c$

MES $02119 \quad 0.3896 c$

MES $02048 \quad 0.3897 c$

MES $02089 \quad 0.4118 d$

MES $02110 \quad 0.413 d$

MES $12694 \quad 0.4185 d$

MES $02120 \quad 0.422 d$ 
$T=9$

Analysis of variance

Variate: Fraction_ADF

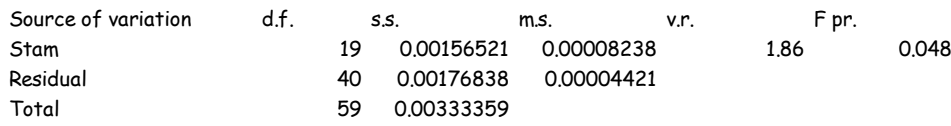

Standard errors of differences of means

\begin{tabular}{|c|c|c|c|}
\hline & & Stam & Mean \\
\hline Table & Stam & MES 02092 & 0.3003 \\
\hline rep. & 3 & MES 02110 & 0.302 \\
\hline d.f. & 40 & MES 02089 & 0.3035 \\
\hline s.e.d. & 0.005429 & MES 02048 & 0.3046 \\
\hline & & MES 00477 & 0.3047 \\
\hline & & MES 11910 & 0.3048 \\
\hline & & MES 12694 & 0.3049 \\
\hline Least & ces of means ( $5 \%$ level) & MES 00476 & 0.3054 \\
\hline & & MES 14178 & 0.3066 \\
\hline Table & Stam & MES 02120 & 0.3069 \\
\hline rep. & 3 & MES 02009 & 0.3082 \\
\hline d.f. & 40 & MES 02054 & 0.3087 \\
\hline I.s.d. & 0.010972 & MES 02053 & 0.309 \\
\hline & & MES 00478 & 0.3107 \\
\hline & & MES 02121 & 0.3112 \\
\hline & & MES 02079 & 0.3118 \\
\hline & & MES 11690 & 0.3142 \\
\hline & & MES 13570 & 0.3149 \\
\hline & & MES 02081 & 0.3177 \\
\hline & & MES 02119 & 0.3201 \\
\hline
\end{tabular}

\begin{tabular}{|c|c|}
\hline $\begin{array}{l}\text { Corresponding address for this report: } \\
\text { P.O. Box } 16\end{array}$ & $\begin{array}{l}\text { Plant } \\
\text { researchers } \\
\text { of }\end{array}$ \\
\hline 6700 AA Wageningen & Wageningen \\
\hline The Netherlands & UR aim to \\
\hline$T+31(0) 317480700$ & utilise plant \\
\hline www.wageningenUR.nl/en/XX & properties to \\
\hline & help solve \\
\hline Confidential PPO/PRI report 2015-6 & issues \\
\hline & concerning \\
\hline & food, raw \\
\hline & materials \\
\hline & They are \\
\hline & $\begin{array}{l}\text { devoting } \\
\text { their }\end{array}$ \\
\hline 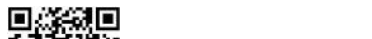 & knowledge of \\
\hline 63 & plants and \\
\hline 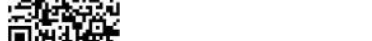 & their up-to- \\
\hline & date facilities \\
\hline & to increasing \\
\hline & the \\
\hline
\end{tabular}

Field Code Changed 
innovative

capacity of

our clients.

In doing so,

they work on

improving

the quality of

life.

The mission

Wageningen

UR

(University \&

Research

centre) is 'To

explore the

potential of

nature to

improve the

quality of

life'. Within

Wageningen

$U R$, nine

specialised

research

institutes of

the DLO

Foundation

have joined

forces with

Wageningen

University to

help answer

the most

important

questions in

the domain

of healthy

food and

living

environment.

With

approximatel

30 locations,

6,000

members of

staff and

10,000

students,

Wageningen

UR is one of

the leading

organisations

in its domain

worldwide.

The integral

approach to

problems

and the

cooperation

between the

various

disciplines

are at the

heart of the

22 | Kies een item.-rapport Xxxx 
